
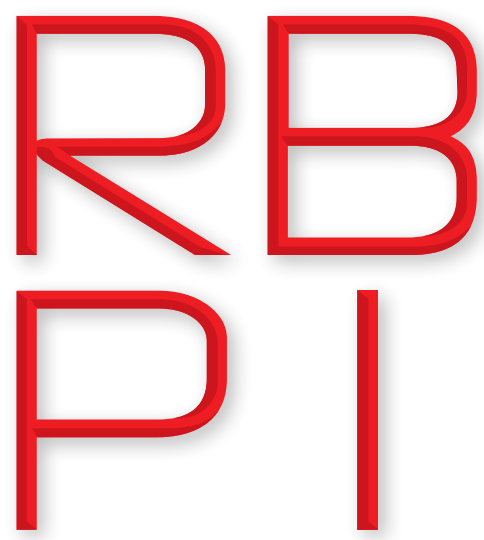

Revista Brasileira de Política Internacional ISSN 1983-3121

http://www.scielo.br/rbpi

\section{Marcelo Santos}

Universidade Estadual Paulista, Faculdade de Ciências e Letras, Araraquara - SP, Brazil (msantos@fclar.unesp.br).

iD ORCID ID:

orcid.org/0000-0003-0151-4284

\section{Global justice and environmental governance: an analysis of the Paris Agreement}

DOI: http://dx.doi.org/10.1590/0034-7329201600116

\section{Copyright:}

- This is an open-access article distributed under the terms of a Creative Commons Attribution License, which permits unrestricted use, distribution, and reproduction in any medium, provided that the original author and source are credited.

- Este é um artigo publicado em acesso aberto e distribuído sob os termos da Licença de Atribuição Creative Commons, que permite uso irrestrito, distribuição e reprodução em qualquer meio, desde que o autor e a fonte originais sejam creditados.
Received: May 5, 2016

Accepted: October 6, 2016

Based on the major normative political theory contributions on global climate justice, the present paper analyzes the new international agreement on climate change, adopted at COP 21 in Paris (2015). Therefore, a literary review of the extensive normative theoretical discussion about global climate justice is made, with special attention to the two approaches that have permeated multilateral political negotiations - historical responsibility and equal per capita emissions. From this normative discussion, this paper recalls the global climate change negotiation process, focusing on the Kyoto Protocol. Next, the analysis emphasizes on the Paris Agreement in an effort to evaluate the normative questions on justice and equity within the environmental governance regime. Finally, the set of conclusions indicates that, although the flexibility of the Agreement has encompassed some dimensions of responsibility, necessity and ability to bear the costs, the most complex dimensions of justice and equity has not been completely solved, which may hinder the operation of environmental governance in a near future.

Keywords: Global Justice; Environmental Governance; Climate Change; Paris Agreement.

\title{
Introduction
}

Aricle three of the United Nations Framework Convention on 1 Climate Change (UNFCCC), which was first open to signature in 1992, at the United Nations Conference on Environment and Development (UNCED), and has already been ratified by 196 countries, acknowledged the problems related to climate change, and determined the need to implement policies to protect the climate system for the benefit of present and future generations of humankind, on the basis of cooperation and equity, and in accordance with the differentiated responsibilities and respective capabilities (UNFCCC 1992, 4-5). Since then, the international community has been discussing themes related to the drafting of a 
global climate agreement. Throughout the long pathway towards the Paris Conference (COP 21), in 2015, the establishment of global governance on climate change has faced lots of difficulties and inoperativeness which were mostly due to the different understandings on cooperation and equity legislation among countries. Such differences resulted in normative deadlocks related to responsibilities to be undertaken, the definition of the efforts to be made, the sharing of the massive costs to address the problem, the distribution of rights to emit, and types of agents that should bear the burdens.

The deadlock about the Kyoto Protocol (1997) was indeed the best example of its kind. According to the principle of differentiated responsibilities, the Protocol set emission reduction targets only to industrialized countries. This lead to a deep division in opinions of developed and developing countries as to matters of cooperation and equity. The refusal by the US to ratify the Protocol, stating that it was not fair to exempt the big polluters among developing countries (China, India, Brazil, for instance), nor to share the costs of mitigation based on historical emissions, is a good example. Furthermore, throughout more than two decades of the UNFCCC, even within the groups of developed and developing countries, there were many divisions arising not only from internal positions of States, but also from normative interpretations of justice and equity. For instance, the different emission profiles and the impacts of emissions and development strategies within the developing countries group, which opposed island States and States vulnerable to the adverse effects of climate changes to oil-producing and fast-growing States.

Altogether, a global agreement on climate change comprises normative challenges which entail a fair distribution of responsibilities and costs, and is, therefore, a matter of global justice. Establishing policies based on cooperation and equity in accordance to differentiated responsibilities and capabilities ultimately involves the ethical problem of finding a fair distribution for climate change mitigation and adaptation costs. Even though national self-interests, distrust among actors, disparities in political, economic and social powers of the parties, and the lack of a global Leviathan make it difficult to reach an agreement, normative theories have contributed by proposing values and principles to pave the way for an equitable international agreement that could lead to a reduction in the emission of greenhouse gases to non-dangerous levels (limit average global temperature rise to $2^{\circ} \mathrm{C}$ above pre-industrial levels).

The discussion of climate change as a matter of global justice has been addressed by several theoretical approaches that deals with different conceptions of justice. Most contributions stem from distributive justice, but the discussion also benefits from redistributive justice interpretations, and both of them reveal implications of generational justice (either intergenerational and intragenerational).

Based on the major normative political theory contributions on global climate justice, this paper analyzes the new international agreement on climate change, achieved at COP 21 in Paris (2015). Therefore, the text is divided into four sections followed by a conclusion. The first two sections comprise a literary review of the extensive normative theoretical discussion about global climate justice. Several principles of justice have been formulated in reference to this question. In this paper, the theoretical review focuses on the two approaches that have permeated multilateral political negotiations. Before the Paris Agreement, the historical responsibility and equal per capita 
emissions approaches supported principles that were used as reference for the discussions on the designing of a global climate governance regime. A number of dimensions and variables make up the design of a global governance regime, but the analysis in this paper will be focused on normative dimensions of justice and equity. This way, the third section will consist of a brief recollection of the historical negotiations about the normative dimensions and the multilateral process, with special attention to the Kyoto Protocol, the major milestone of these negotiations. The forth section will address the Paris Agreement itself and the normative matters on justice and equity. Following almost 20 years of frustrations in post-Kyoto negotiations, countries managed to reach an agreement on universally accepted rules, an essential condition for any international governance regime.

\section{Historical responsibility}

The theoretical approach to historical responsibility addresses each country's different emission level and responsibility for the unsustainably high concentration of carbon dioxide in the atmosphere on the basis of past emissions. From a normative standpoint, the argumentation is based on the idea that the historically greatest greenhouse gases emitters are responsible for the current climatic conditions of our planet and, therefore, should pay for that. Eric Neumayer (2000) employs three arguments to advocate this historical approach that largely summarizes the entire theoretical argumentation that supports this perspective. According to Neumayer (2000, 187-188), the first argument is of scientific nature, for noting that global warming is a consequence of historical greenhouse gases emissions. The second point is based on retributive justice. The Polluter Pays Principle (PPP), adopted by the Organization for Economic Co-operation and Development (OECD) since 1974, says that countries responsible for environmental damages should bear the costs of solving the problem, repairing the damage. The third one is supported by the assumption of equal opportunities to use global atmosphere resources, that is, given the limited capacity of the atmosphere to absorb greenhouse gases without adverse effects, the historically greatest emitters shall emit less in the present and in the future, while the historically smallest emitters have the right to emit more in the present and in the future.

The theoretical framework of the approach to the historical responsibility can be complemented with the debate about the Beneficiary Pays Principle (BPP). Such principle suggests that the countries that benefited from the climate changing activities should bear the costs of mitigation and adaptation, and further compensate countries affected by them (Page 2012, 303; Baatz 2013, 97). In Christian Baatz $(2013,97)$, the BPP is grounded in corrective justice, i.e., its normative force consists in rectifying an injustice, which is perfected by a compensation by the beneficiary to the affected countries. There is a causal relationship: whenever someone benefits from a wrongdoing, even if involuntarily, it owes an obligation to the victim. Edward Page (2012), on the other hand, is convinced that BPP has normative capability in terms of distributive justice, that is, it does not focus on the offense or the penalty, but on the redistribution of undue benefits and costs. In order to defend BPP, Page (2012, 309-310) employs the phrase "unjust enrichment", suggesting 
that the States shall bear the costs of the responses to climate change problems according to the benefits they earned from the activities that caused climatic disadvantages to other States, even though the production, acquisition or intergenerational transference of these benefits have incurred in no irregularity.

There many divergences as to understanding and applying the historical responsibility approach. There are also many theoretical disputes about PPP and BPP as ethical and distributive justice principles. As we could note, the major objections to the historical responsibility principle are supported by arguments like: unawareness by past generations of the prejudicial consequences of their greenhouse gases emissions (Grubb 1995, 491; Jamieson 2001, 301; Singer 2002, 38-39); present generations in developed countries should not be hold responsible for damages brought about by past generations (Beckerman and Pasek 1995, 410); scientific and technological benefits of emissions has also contributed to improve the standard of living in developing countries (Grubb, Sebenius, Magalhaes and Subak 1992,316); climate change science faces many difficulties to determine exactly when emission levels have become harmful (Miller 2009, 131); in addition to the practical difficulties to effect the principle, which renders it unfeasible without an appropriate international coercive force (Traxler 2002, 122).

David Miller acknowledges the historical responsibility problem, reluctantly though, since he does not see it as a key for an agreement to fight global warming. According to Miller $(2009,130)$ those countries responsible for the greatest emissions in the past cannot be morally condemned or held responsible for the impacts of those emissions in the future, for when they took those actions, they were not aware they would be prejudicial. This does not mean, however, that these countries should not bear the responsibilities of neutralizing these damages. For Miller, the historical responsibility principle should not be applied for those emissions occurred before the international scientific community has ascertained the emissions were provoking climate changes and that a fair agreement to regulate such emissions was required. This way, Miller (2009, 136-137) suggests the historical responsibility principle should be applied to the emissions occurred after 1985 or 1990, when the catastrophic effects of the elevated carbon emission levels had become more evident. From this date on, the countries responsible for the greatest emissions should bear most part of the costs of climate change mitigation. Miller $(2009,145-146)$ further adds to his argumentation the idea that such costs should be entirely born by the countries that do not face endemic poverty, since countries with endemic poverty do not show the required capability to meet this commitment, and, where applicable, should be authorized to rise their emissions for the purpose of overcoming poverty. Lastly in reference to the way the costs should be shared among the greatest emitters, Miller $(2009,151)$ suggests the Equal Sacrifice Principle (ESP), according to which those societies that do not face endemic poverty and whose emissions have increased after the date set would have higher costs and sacrifices (less emissions), while those societies whose emissions decreased, would bear the lowest costs and sacrifices.

Peter Singer $(2002,31)$ recognizes the history of unequal emissions among the countries, and states that, in addition to their proportionally higher contribution to the current concentration 
of carbon dioxide in the atmosphere, developed countries have already consumed a large part of planet's capacity to absorb carbon dioxide. Resorting to John Locke's theory of property, Singer (2002, 31-32) affirms that developed countries have not left the same proportion of absorptive capacity for developing countries. This, however, does not make him adopt a principle of historical responsibility for the emissions. Singer only suggests that, until 1990, the year in which the first assessment report by the Intergovernmental Panel on Climate Change (IPCC) was published, people were not sufficiently aware about the level of emissions and their causes and effects. Singer (2002, 43-44) pragmatically believes that neglecting historical emissions would help to achieve an international consensus based on a commitment to equaling per capita emissions. Dale Jamieson $(2001,301)$ resorts to the same pragmatism when he states that emissions before 1990 are not a moral equivalent to the emissions after this date, since they did not result from intentional efforts.

Simon Caney $(2005 ; 2006 a ; 2010 ; 2012 a)$ also reflected about the approach to the historical responsibility. His analysis addresses the climate change theme linked to other normative issues, such as poverty, commerce, development and human rights, composing what he terms integrationist approach. This approach opposes the so-called isolationist or atomistic analyses, that is, those that consider the normative issues on climate change without taking into account the other dimensions related to the problem. According to Caney $(2005 ; 2012 \mathrm{a})$, the integrationist perspective is crucial for the debate of matters like: assigning responsibilities; distributing licenses to emit greenhouse gases; assessing climate impacts; and mitigation, adaptation and compensation policies.

For Caney $(2005 ; 2010)$, the PPP itself is insufficient and can be highly criticized; however, a promising possibility would be to find a way to combine this principle to the Ability to Pay Principle (APP), composing a hybrid justice approach to climate change. Caney admits that, although the PPP is attractive, i.e., the country that created the problem is morally bound to dealing with the costs, its application is difficult. According to Caney (2006a, 467), one of the problems is identifying the drivers of climate changes. Pursuant to his argumentation, there are different types of actors whose actions contributes to global climate change, such as State institutions, including national government and subnational political units, corporations, subjects, and international institutions. For Caney (2006a, 468-471), another problem is the impossibility to repair the damages, since many actors responsible for those actions do not exist anymore, since subjects died, companies closed, and States disappeared. According to Caney (2010,207), when a long and continuous time period is considered, the determination of the causal contribution of each action to climate change and the assessment of its costs is such an undefined and speculative task that it may not be feasible or fair. Not to mention the problems related to present generations paying for the emissions of greenhouse gases by past generations; the general ignorance about the effects of greenhouse gases emissions on climate changes; and the failure to meet the obligation to not emit excessive amounts of greenhouse gases $(2005,766-767)$. In light of these problems, Caney $(2005,767)$ points out that the PPP approach may be applied only to those actors that have been emitting excessive amounts of greenhouse gases since 1990. The principle could, therefore, be applied to the recent past and to the present, and also to the future, informing quotas that, once exceeded, should be compensated for by the actors. This would be a solution for the problem of ignorance. 
For the distribution of the burdens related to the fight against climate change, however, Caney complements his reviewed version of the PPP with a specific version of the Ability to Pay Principle (APP). This principle says that the States should bear climatic responsibilities in proportion to their relative abilities to bear the burdens, that is, those who have more resources should make greater efforts. In this hybrid model, Caney develops a perspective to determine responsibility that is based on a distinction between causality and responsibility to repair. As noted further on, for Caney $(2010,213)$, the APP is indifferent to the cause of the damage, its emphasis is on who can repair this damage. He proposes that, regardless of the degree of causal contribution, the most favored nations have an obligation to pay for mitigation and adaptation costs, at least to the extent sufficient to cover those emission of pollutants they are not able or willing to pay. This way, in accordance to Caney, the basis of the moral responsibility to address climate change is not related to the history, nor to prejudices to the interests of other nations, but to whoever is capable of correcting the damages. Caney $(2010,218)$ further completes his argumentation suggesting that, if mitigation and adaptation costs should be paid by rich countries, pro rata to their wealth, a distinction between fair and unfair enrichment would be required, the latter bearing higher responsibilities. Caney's hybrid approach comprises a lexical order for the application of principles: PPP is applied first, and APP is applied to those instances not covered by PPP.

In opposition to those arguments contrary to the historical responsibility approach, Stephen M. Gardiner $(2004,581-583$; 2010, 56-58) points out that for no reason should the fact that past emissions be ignored since it consists in a matter of justice, and that it is both practical and theoretical. Gardiner $(2010$, 56-58) refutes the argument of the ignorance on the effects of emissions. For the author, the fact that it is not possible to accuse countries for actions whose effects they were unaware of does not mean they should not be held responsible. Gardiner also refutes the argument in which present generations in developed countries should not be held responsible for results not caused by them but by past generations. For him, the responsibility applies to States and not to individuals, who inherit the debts and the benefits of living in a given territory. Gardiner also overthrows the argument supporting that taking past emissions into consideration would hinder a global agreement to fight climate changes. On the contrary, Gardiner suggests that failing to take past emissions into account would hinder an agreement, since many nations would not accept it. And the absence of a coercive power to enforce the agreement globally does not mean the lack of other external coercive instruments, such as, for instance, trade sanctions.

\section{Equal per capita emissions}

The equal per capita emissions approach is supported by the idea that the atmosphere is a global common, to which every person has the same right to use. These way, acceptable carbon emissions should be equally distributed among the entire world population and made available proportionally to the countries, based on their populations (Baer 2002; Singer 2002; Moellendorf 2009; Meyer 2000). According Aubrey Meyer's (2000, 305) approach in “Contraction 
and Convergence", countries need to reach an agreement on a long-term global stabilization level for the concentrations of greenhouse gases in the atmosphere, which implies an extension for a contraction. Next, countries must negotiate a convergence date setting the moment when the emissions assigned to each one should converge to equal per capita rights. Throughout this convergent period of emissions towards a sustainable and equitable level, developing countries could rise their emissions while developed countries should only reduce. The developed countries that needed emissions exceeding their quota, could buy the right to emit from developing countries with surplus quotas. This could create a flow of income for developing countries.

From the "Contraction and Convergence" normative perspective, Peter Singer $(2002,35)$ also defends the equal per capita emissions. Singer assumes the thesis that the atmosphere is a global common with a limited capacity to receive carbon dioxide without resulting in severe climate changes, hence everybody should have the right to emit carbon dioxide equally, with no regard to the place where they may leave on earth. This way, according to Singer, there is no justification for assigning disproportional quotas to the countries. According to Peter Singer $(2007,2)$, per capital quotas can be calculated as follows:

Establish the total amount of greenhouse gases that we can allow to be emitted without causing the earth's average temperature to rise more than two degrees Celsius (3.6 degrees Fahrenheit), the point beyond which climate change could become extremely dangerous; divide that total by the world's population, thus calculating what each person's share of the total is; allocate to each country a greenhouse gas emissions quota equal to the country's population, multiplied by the per person share; finally, allow countries that need a higher quota to buy it from those that emit less than their quota.

Singer $(2002,43)$ admits, however, that population size is a problem for applying this principle in the long run. In light of this, he proposes that per capita distribution is based on the estimated population of any given country in future dates, such as, for example, United Nations (UN) population estimates for the next 50 years.

According to Singer's $(2002,46-49)$ proposal, the costs to mitigate climate changes would be shared by each country's volume of emissions, being largely born by the biggest emitters, which would have a limit for their emissions. He indeed admits that this proposal could have serious impacts on the economy of developed countries since they should significantly reduce their emissions. Therefore, he accepts the trading of carbon emissions among countries with disproportional emissions. He believes such a measure would be feasible, effective, and fair, because it would not only reduce carbon dioxide emissions to sustainable levels, but also promote a large transference of economic resources from rich to poorer countries. Singer suggests that the United Nations (UN) monitors this quota trading.

David Miller $(2009,148)$ on the other hand, refuses the assumption that every person should have an equal per capita right to emit per year. According to Miller, this principle is problematic because it does not take into account each society's different ability to reduce emissions. Conversely, Miller $(2009,150)$ suggests that the distribution of the costs to mitigate climate changes should 
follow the Equal Sacrifice Principle (ESP), which means that, without prejudice to their vital interests, all societies should make the same sacrifices to address the problems, as related to their current standard of living. The focus then is not equally sharing carbon emissions, but making equal sacrifices in terms of loss of yield or consumption. For this proposal, we could say, the unequal amount of emissions is not a focus of concern.

Simon Caney (2012b, 260) also disagree with the thesis that stipulates rights to emit should be distributed according to an equality principle, that is, the equality per capita approach. For him, this perspective consists in an atomistic approach that does not take other climate-related responsibilities into account, such as poverty, education and health, for instance. Furthermore, this point of view ignores the fact that emissions can be substituted, that is, a lot of the specific goods produced by activities that generate emissions can be provided by other means, such as through energy efficiency, alternative energy sources and alternative agricultural practices. Accordingly, Caney's focuses on the fair distribution of permissions to emit greenhouse gases, and not the equality per capita. Caney $(2006 \mathrm{~b}, 255)$ points out that climate changes are unfair because they threaten and violate fundamental human rights, such as to life, alimentation, water and health. Under Caney's perspective, these are rights people have for their own humanity, that are not granted by the nation or State where they were born, or for any other actions they have done.

Gardiner also raises some concerns as to the application of the equal per capita principle. According to Gardiner $(2004,584)$, this principle does not consider the fact that emissions can have very different roles in the life of people in the different regions of the world. Other identified obstacle is the possibility that the adoption of this principle has different implications for different countries, for instance, countries with the greater emissions should undertake more dramatic reductions. In Gardiner's words $(2010,59)$, the supporters of the per capita approach declare that this problem could be overcome by means of the emissions trading. Gardiner does not think this is a simple solution, since this trading faces a practical feasibility problem. Furthermore, the proposal could deviate from the initial idea of equality, since there is no guarantee the transferences of resources will be well distributed among receptors. And, as Gardiner points out, there is also the moral issue of paying for a polluting behavior.

The first two sections show that the normative theoretical discussions are not free from disagreements as to the interpretation of the principles of justice. Although there is some consensus that the discussion should be held in terms of the general principles of historical responsibility, equality and capability to bear the costs, we can see that normative political theory not only interprets these principles differently, but also assigns different weights to them when it is necessary to balance them to reach a potential agreement.

\section{Global justice and environmental governance}

From 1992 to the Paris Conference, the designing of global environmental governance institutions has been characterized by deadlocks with reference to the foregoing normative questions. Throughout this period, in spite of all disagreements on the reasons, one could find 
in the normative literature a consensus that developed countries should lead the efforts and bear the charges related to global climate problems. With the adoption of the Kyoto Protocol, the dimensions of equity and cooperation as differentiated responsibilities and respective capabilities were conducted as mitigating actions, considering the reduction of emissions as burden to be borne by developed countries, which were considered responsible for the problem, following a top-down approach. In addition to other deadlocks — historical or recent responsibility; biggest polluters among developing countries were not listed in the Agreement; the right to economic development for developing countries - negotiations failed at these milestones as a result of the general opposition of developed countries to developing ones.

The designing of the Protocol with a dichotomic differentiation into Annexes of countries (listed in Annex I, developed countries; not listed in Annex I, developing countries), and a slim chance of reaching an agreement among the main countries was seen by many theorists as the major reason for the negotiation failures. According to Robert O. Keohane and David G.Victor (2010, 5): "In practice, because Kyoto placed no obligations on developing countries and because the United States never ratified the agreement, its practical effect was narrow, thin and ultimately symbolic". For Jorge E. Viñuales $(2011,225)$, the distinction between countries listed and not listed in Annex I for the purposes of sharing the obligations has not been sensitive enough to differences in levels of emissions, human development, financial resources, technological capabilities, population and other criteria relevant for a fair distribution of benefits and costs from climate changes fighting. In their analysis of the economic rise of China and the role of the country in climate negotiations, Hong-Yuan Yu and Song-Li Zhu $(2015,62)$ pointed out another important question resulting from the difficulties of this format of negotiation, that is the conflict between the countries with high emissions and those with low emissions.

Designing an agreement on the basis of equity and justice within a global context of extreme inequalities is not an easy task. The costs and burden constraints in order to achieve a global climatic policy has always made the negotiations difficult among countries which, for their internal conditions, interpret the phenomenon in different ways. During negotiations, equity and justice principles are indeed subject to variations resulting from the extremely unequal position each country occupies in global power hierarchy. And this is true not only in regard to developed and developing countries, but also to developing countries, that have different levels of development, vulnerabilities, responsibilities and capabilities. We could say that, in general, an imprecise morality prevails in the international system, the definition of which depends on the power of the country and its national interests, which makes the conception of unique justice and equity principles difficult. Such a situation becomes more complex as, depending on the concerned theme, the negotiations get more fragmented, as is the case of climate change, and this makes a common perception of justice and equity by the parties difficult.

The Paris United Nations Conference on Climate Change (COP 21) was able to overcome many of these deadlocks resulting from particularistic views about the normative questions, and to further coordinate different principles with the acceptance of all, achieving results which were more satisfactory in terms of compatibility between the international agreement and the preservation 
of national sovereignties. From the Durban COP (2011), all the countries agreed to work aiming at reaching a new agreement in 2015 and, hence, created the Ad Hoc Working Group on the Durban Platform for Enhanced Action (ADP). They were expected, thus, to end the strict division between developed and developing countries with a common framework that would commit all countries, including reference to regular notifications about emissions and implementation actions, and the submission of international evaluations. This way, every country was stimulated to present national commitments. This resulted in a higher bottom-up participation, mainly from developing countries, and culminated in the presentation of 188 Intended Nationally Determined Contributions (INDCs) at the Paris Conference. Not to mention the US-China joint statement on actions and targets to cope with climate change from 2020 onward, dated November 2014.

Following bilateral and plurilateral arrangements, COP 21 has reached a multilateral agreement on a global climate regime applicable to all parties, setting forth provisions on financing, technology, and capacity-building, and also creating a transparent and verifiable vigilance mechanism for mitigation and adaptation actions. The Paris Agreement is a legally binding instrument as to the review and the assessment of duties, but it is not binding in terms of emissions and individual financial contributions. Countries like the US, China, India do not accept legally binding obligations in such cases, resorting to matters of national sovereignty, such as the preservation of the prevalence of their domestic decisory spaces over international agreements.

A number of decisions and variables make up the designing of a global governance regime. The following analysis of the Paris Agreement will be focused on the normative dimensions of justice and equity.

\section{The Paris Agreement}

In its Article 2, paragraph 2 of the Agreement, it is restated the UNFCCC principle of equity and cooperation, including the common but differentiated responsibilities and respective capabilities, in the light of different national circumstances (UNFCCC 2015, 22). Established since the very beginning of the United Nations Framework Convention on Climate Change (UNFCCC), these principles had been subject to different interpretations by parties of the negotiations and in the normative theoretical debate. The Paris Agreement set forth a definition of the operation of these principles, featuring the sentence "in the light of different national circumstances" as a new term.

The matter of common but differentiated responsibilities became controversial following the proposal Brazil submitted to the Ad Hoc Group of the Berlin Mandate (UNFCCC 1997), in 1997. Grounded in the Polluter Pays Principle, such proposal presented the responsibility theme in terms of historical responsibility, specifying that the burdens were distributed among the countries included in Annex I (industrialized countries) according to their degree of contribution to climate changes. The Preamble of the United Nations Framework Convention on Climate Change had already acknowledged, since 1992, "that the largest share of historical and current global emissions of greenhouse gases has originated in developed countries" (UNFCC 1992, 1). 
In Cancun, 2010, COP 16 incorporated the historical responsibility approach, recognizing "that the largest share of historical global emissions of greenhouse gases originated in developed countries and that, owing to this historical responsibility, developed country Parties must take the lead in combating climate change and the adverse effects thereof" (UNFCCC 2010, 8). Since then, as mentioned, the interpretation and the normative application of this principle has been one of the themes that divided developed and developing countries, chiefly when the interpretations proposed by developing countries suggested proportional compensation, which was refused by developed countries.

The analysis of the Paris Agreement reveals that developed countries will not adopt any mechanism to fight the adverse effects of climate change that is based on a proportion of past emissions. Seen in light of differentiated responsibilities and respective capabilities, and taking into consideration the different national circumstances, responsibilities questions have been addressed in several articles, which acknowledge that developed countries should lead the fight to climate changes meeting economy-wide absolute emission reduction targets (Article 4), providing financial resources to help developing countries in mitigation and adaptation efforts (Article 9), transferring technology to developing countries (Article 10), and increasing the support to capacity-building actions in developing countries (Article 11). Noteworthy, developing countries with the capability to complete these actions may undertake them as well, and every country should present the actions taken to fight climate changes. One could say that the Agreement adopted a hybrid approach in regard to justice and equity, stipulating that States undertake climatic responsibilities proportionally to their relative capabilities to bear the burdens, that is those who have more resources should make greater efforts, but the commitment is applicable to all States. The new term "in the light of different national circumstances" intends to preserve national sovereignties, a fact that makes the more complex dimensions of justice and equity, such as emissions reduction, for instance, non-binding.

The final document also restated the long-term target, which had been established in Copenhagen and confirmed in Cancun, limiting average global warming to $2^{\circ} \mathrm{C}\left(3.6^{\circ} \mathrm{F}\right)$ above pre-industrial levels, while stimulating the parties to limit the rise to $1.5^{\circ} \mathrm{C}$, one of the most important requirements by the developing countries that are more vulnerable to global warming (Article 2, paragraph 1A). Of note, following an effort by European Union (EU), 106 States agreed on the $1.5^{\circ} \mathrm{C}$ effort. From a normative standpoint, the reaffirmation of such target brought attention, once more, to the problem of sharing the global mitigation effort in terms of equity. This question has become more complex since 2014, following the publication of the IPCC Fifth Assessment Report (AR5) (IPCC 2014), which set forth, in scientific grounds, that in order to keep global warming below two degrees Celsius with a probability $>66 \%$, carbon emissions should be limited to one trillion of tons (1.000 Gt of CO2). This document has made clear the limits of our planet's carbon budget.

The Agreement made no direct reference to carbon budget limits and did not address the sharing of mitigation efforts in terms of dividing the atmospheric space available for emissions nor commitments based on equal per capita allocation of rights to emit, as suggested by normative 
theorists and diplomacies from countries like India. Through the Agreement, the parties agreed on the adoption of the Intended Nationally Determined Contributions (INDCs), individual pledges made by each country with a view to meet the UNFCCC targets which were expected since COP 19 and were defined on COP 20 through the "Lima Call for Climate Action" (UNFCCC 2014). Under the Agreement, INDCs should be clearly and transparently presented, redefined every five years, and should also show progression of mitigation efforts and set forth fair and ambitious objectives, in light of its national circumstances. Based on equity and on science, every five years a global stocktake focused on mitigation, adaptation and implementation and support means will inform the countries about what should be done in future actions, support and international cooperation (Article 14, paragraphs 1, 2 and 3).

In this case, one can say that the scientific reports by the Intergovernmental Panel on Climate Change (IPCC) about the rhythm of emissions, worldwide velocity of decarbonization and limits for dangerous climate changes, must be adopted as one of the basis for the evaluation of the actions taken in order to ensure the average global temperature target is met and to determine what needs to be done. However, even though participation in the global stocktake is mandatory for all the countries, the evaluation will be conducted based on the whole set of efforts rather than individually. Thus, the stocktake will focus on what needs to be done rather than who needs to do it or how much needs to be done.

As to who needs to do and how much needs to be done, questions encompassing equity dimensions, the Agreement says that INDCs should reflect its common but differentiated responsibilities and respective capabilities, in light of different national circumstances (Article 4, paragraph 3). From this standpoint, the differentiation in mitigation responsibilities was settled by means of the expectation that developed countries keep the economy-wide absolute emission reduction targets, while developing countries will be stimulated to move to similar targets without the word "absolute" (Article 4, paragraph 4) though. According to the text, the actions to meet the temperature targets should be undertaken on the basis of equity, and in the context of sustainable development and efforts to eradicate poverty. (Article 4, paragraph 1). The Agreement also stipulates that INDCs by the least developed countries and Small Island developing States should reflect their special circumstances (Article 4, paragraph 6). On the one hand, these provisions, though in a non-binding way, ensure developed countries lead the emission reduction process, even though they do not take into account the amount of reduction required for each country individually in light of the global carbon budget. On the other hand, these provisions ensure that the global climate agreement will make no restrictions as to the development perspectives for least developed countries, and do not take the global carbon budget limits into consideration as well.

The emission reduction strategy based on individual target commitments by the countries has been adopted under the allegation to protect national sovereignty. Although the EU, the G77 and Island States (AOSIS) have insisted on a legally binding regime for this question, the US and other countries did not accept this regime. Such fact was a sine qua non condition for reaching the agreement. In this case, it seems that the aspect Robert O. Keohane (1986) deemed fundamental for multilateral cooperation was present, that is, cooperation must be consistent 
with national sovereignty. Furthermore, even though INDCs responsibilities does provide for the differentiation of responsibilities, one can say that the question of sharing the efforts to reduce emissions is not completely resolved. Especially if the limits of our planet's carbon budget are taken into consideration.

Of note, the Agreement indicates with concern that, in order to maintain the estimated average global temperature, greater efforts than those related to the INDCs will be required, the Agreement (paragraph 17) reads:

Notes with concern that the estimated aggregate greenhouse gas emission levels in 2025 and 2030 resulting from the intended nationally determined contributions do not fall within least-cost $2^{\circ} \mathrm{C}$ scenarios but rather lead to a projected level of 55 gigatonnes in 2030, and also notes that much greater emission reduction efforts will be required than those associated with the intended nationally determined contributions in order to hold the increase in the global average temperature to below $2^{\circ} \mathrm{C}$ above pre-industrial levels by reducing emissions to 40 gigatonnes or to $1.5^{\circ} \mathrm{C}$ above pre-industrial levels by reducing to a level to be identified in the special report referred to in paragraph 21 below.

In a recent study published in Nature based on 160 INDCs presented until December 2015, Joeri Rogelj et al. (2016) showed that altogether the presented INDCs would lead to an increase of about $2.6-3.1^{\circ} \mathrm{C}$ in global temperature until 2100, and that the entire carbon budget to limit the warming to $2^{\circ} \mathrm{C}$ with probability $>66 \%$ (IPCC 2014) could have been emitted until 2030. That is, the set of INDCs is not yet sufficient to limit the warming to well below $2^{\circ} \mathrm{C}$, and it must be enhanced. The study also admits that, since INDCs commitments comprise conditional statements, such as, for instance, if a country will only implement ambitious emission reductions after receiving funding from other countries, future emissions of about 6 billion of tons of $\mathrm{CO}^{2}$ are uncertain.

Uncertainties of such dimensions become more complex as the INDC encompasses future promises, and not exactly the things countries are doing. This way, it is possible that, in future negotiations, in case some countries fail to achieve INDCs results, distancing themselves from the long-term temperature target, the problem to share global mitigation efforts in terms of justice and equity between countries may be seen again. Actually, it is not possible to affirm that INDCs will represent an equitable distribution of the mitigation charges.

Widely supported by developing countries, mainly by the Alliance of Small Island States (AOSIS) and African countries, the adaptation efforts gained the same normative status of mitigation within the climate regime, under Article 7. There is no specific obligation for developed countries and a special treatment for developing countries, especially to those more vulnerable to the adverse effects of climate change, even though there is no list of such countries. Of note, the adaptation efforts rely widely on matters of financing, capacity-building, transference of technology to developing countries, dimensions that can be seen in the Agreement, but it does show several gaps and lack a clear definition of procedures. 
With respect to financing, Article 9, paragraphs 1 and 2 of the Paris Agreement says that developed countries should continue taking the lead on the efforts to gather financial resources for the mitigation and adaptation in developing countries, while it suggests that developing countries with the proper conditions should provide this resources voluntarily. In such case, the group of countries that could contribute is larger, as requested by developed countries. The Agreement has also postponed the target that had been set in COP 15 (Copenhagen) from 2020 to 2025, for the provision by developed countries of US\$100 billion a year in resources, from public and private, bilateral and multilateral sources, in order to meet the needs of developing countries (UNFCCC $2015,8)$. As to the monitoring, in addition to the reporting of provided financial resources, developed countries committed to send every two years "quantitative and qualitative indicative information" about future support, including, "as available”, projected levels of public financial resources (UNFCCC 2015, 27). Paragraph 4 set the least developed countries vulnerable to the adverse effects of climate changes and the small island developing States as top priority for the provision of funds. This way, developing countries are not all alike.

Countries and their respective specific amounts are not defined. There are no mandatory targets in this regard, a kind of decision that, in the US for instance, would depend on Senate ratification, not only on the government. The Agreement has not used the terms "new and additional" for financing, as developing countries advocated historically, out of fear that the financial flows for climatic actions would come from the transference of funds from international assistance. In regards with financing mechanisms, the Agreement accepted the services of the Green Climate Fund and the Global Environment Facility, in response to the wishes of the developing countries. Considering the differences between promises and resources effectively transferred to these funds and the lack of a more accurate financing package, disagreements on equitable and effective funding may persist for the next years.

The Agreement also recognized the importance of averting, minimizing and addressing loss and damage (Article 8). An old demand of small island countries (Alliance of Small Island States - AOSIS) and other countries highly vulnerable to climatic impacts, the article on loss and damages reinforces the Warsaw International Mechanism, established at COP 19, Warsaw, 2013, providing for the sharing of knowledge on risk management, financial and technical support and cooperation. Other request by AOSIS that has been granted is the consideration of loss and damage as a distinct component within the regime, since until COP 21 it was under the scope of adaptation. The Agreement also established that the mechanism to address loss and damage does "not involve or provide a basis for any liability or compensation" (paragraph 52). According to the position advocated by the developed countries, mainly the US, out of fear of legal actions by countries affected by climate disasters claiming for accountability and compensation.

The phrase carbon market is not even mentioned in the document; the new agreement only acknowledges that the use of tools like carbon pricing is an important incentive for emission reduction activities (paragraph 137). Article 6, paragraphs 1, 2 and 3 recognizes that some parties may choose to pursuit voluntary cooperation in the implementation of their INDCs, that is, use internationally and voluntarily transferred mitigation outcomes. 
The Agreement is supported by a large framework of transparency and accountability, which involves commitments for all the parties, with clear rules and completion deadlines. This position was strongly supported by the European Union (EU) in opposition to China, which advocated for a weaker international transparency framework. In order for them to be evaluated, countries should submit biannually a national inventory report of anthropogenic emissions by sources and removals by sinks of greenhouse gases, except for less developed countries and Small Island States, which may submit this information voluntarily. The perspective is to establish a structure to monitor, measure, review and verify actions countries are taking to reduce emissions. For the first time, developing countries have been included in transparency assignments, although they have gained some flexibility in terms of level of requirements, according to paragraphs 1, 2 and 3 of Article 13:

In order to build mutual trust and confidence and to promote effective implementation, an enhanced transparency framework for action and support, with built-in flexibility which takes into account Parties' different capacities and builds upon collective experience is hereby established. (...) The transparency framework shall provide flexibility in the implementation of the provisions of this Article to those developing country Parties that need it in the light of their capacities. The modalities, procedures and guidelines referred to in paragraph 13 of this Article shall reflect such flexibility. (...) The transparency framework shall build on and enhance the transparency arrangements under the Convention, recognizing the special circumstances of the least developed countries and small island developing States, and be implemented in a facilitative, non-intrusive, non-punitive manner, respectful of national sovereignty, and avoid placing undue burden on Parties.

In light of these terms, it is possible to say that the Paris Agreement transforms transparency in the major regulatory mechanism intended to building trust among the parties. Especially when taking into consideration that several provisions are not binding.

\section{Conclusion}

Following decades of deadlocks in climate changes negotiations characterized by divergences and distrusts among the parties as to several normative questions which emphasized on principles of responsibility, capability, equality, among others, the Paris Conference managed to achieve more concrete diplomatic results. Without waiving their national and sovereignty interests, the parties achieved a widely accepted agreement. With a flexible and not much binding perspective (except for the review and evaluation of obligations), the Agreement set forth provisions on mitigation, adaptation, financing, technology and capacity-building, and also created mechanisms dedicated to transparency, monitoring and evaluation of the actions taken by the countries, which were defined according to an ultimate global temperature objective. 
From the standpoint of normative political theory on justice, the deadlocks resolved in Paris pointed, altogether, to an attempt to balance the Agreement, involving different dimensions of responsibility, need, and ability to bear the costs. This way, it was laid down that developed countries will bear the highest costs of the mitigation and adaptation process, as well as undertake emission reduction targets more ambitiously than developing countries, which in turn will start undertaking responsibilities in such area, mainly the large emitters. The least developed countries and small island States received priority treatment among the group of developing countries. Every nation must contribute at some extent to the cooperation regime on climate changes.

However, if flexibility was, on the one hand, the way to render equity and cooperation among States with different interests and capabilities into practice within a decisory regime based on intergovernmental consensus. On the other hand, it may have limited the agreement's equity and justice scopes, because the most complex dimensions have not been completely solved and are based on non-binding commitments. The question on sharing the efforts for the reduction of emissions addressed in a non-binding way and with no reference to the global carbon budget limits, as well as the weak mechanisms for financing, adaptation, capacity-building and transference of technology for developing countries, may difficult the operation of environmental governance in terms of equity and justice, bringing about new disagreements in the near future.

\section{Bibliographic references}

Baatz, Christian. "Responsibility for the past? Some thoughts on compensating those vulnerable to climate change in developing countries." Ethics, Policy and Environment 16, issue 1 (2013): 94-110.

Baer, Paul. "Equity, greenhouse gas emissions, and global common resources." In Climate change policy: a survey, edited by Stephen H. Schneider, Armin Rosencranz, and John O. Niles, 393-408. Washington, D.C.: Island Press, 2002.

Beckerman, Wilfred and Pasek, Joanna. "The equitable international allocation of tradable carbon emission permits." Global Environmental Change 5, issue 5 (1995): 405-413.

Caney, Simon. "Cosmopolitan justice, responsibility and global climate change." Leiden Journal of International Law 18, (2005): 747-775.

Caney, Simon. "Environmental degradation, reparations, and the moral significance of history." Journal of Social Philosophy 37, issue 3 (2006a): 464-482.

Caney, Simon. "Cosmopolitan justice, rights and global climate change." Canadian Journal of Law and Jurisprudence 19, issue 2 (2006b): 255-278.

Caney, Simon. "Climate change and the duties of the advantaged." Critical Review of International Social and Political Philosophy 13, issue 1 (2010): 203-228. 
Caney, Simon. "Global justice, climate change, and human rights." In Leadership and Global Justice, edited by Douglas A. Hicks and Thad Williamson, 91-111. New York, USA: Palgrave Macmillan, 2012.

Caney, Simon. "Just emissions." Philosophy \& Public Affairs 40, issue 4 (2012b): 255-300.

Gardiner, Stephen. "Ethics and global climate change." Ethics 114, issue 3 (2004): 555-600.

Gardiner, Stephen. "Ethics and climate change: an introduction." Wiley Interdisciplinary Reviews: Climate Change 1, issue 1 (2010): 54-66.

Grubb, Michael, Sebenius, James, Magalhaes, Antonio and Subak, Susan. "Sharing the burden." In Confronting climate change: risks, implications and responses, edited by Irving M. Mintzer, 305-322. Cambridge, UK: Cambridge University Press, 1992.

Grubb, Michael. "Seeking fair weather: ethics and the international debate on climate change." International Affairs 71, issue 3 (1995): 463-496.

Intergovernamental Panel on Climate Change (IPCC). Climate Change 2014: Synthesis Report. Contribution of Working Groups I, II and III to the Fifth Assessment Report of the Intergovernmental Panel on Climate Change.

Jamieson, Dale. "Climate change and global environmental justice." In Changing the atmosphere: expert knowledge and global environmental governance, edited by Clark A. Miller and Paul N. Edwards, 287-307. Cambridge, Massachusetts: MIT Press, 2001.

Keohane, Robert O.. "Reciprocity in International Relations." International Organization 40, issue 1 (1986): 1-27.

Keohane, Robert O. and Victor, David G. "The Regime Complex for Climate Change." Discussion Paper 2010-33, Cambridge, Mass.: Harvard Project on International Climate Agreements, January 2010. 1-30.

Meyer, Aubrey. Contraction \& Convergence: the global solution to climate change. United Kingdom: Green Books, 2000.

Miller, David. "Global justice and climate change: how should responsibilities be distributed?" In Tanner lectures on human values 28, edited by Grethe B. Peterson, 119-156. Utah: University of Utah Press, 2009.

Moellendorf, Darrel. "Treaty norms and climate change mitigation." Ethics and International Affairs 23, issue 3 (2009): 247-265.

Neumayer, Eric. "In defense of historical accountability for greenhouse gas emissions." Ecological Economics 33, (2000): 185-192.

Page, Edward. "Give it up for climate change: a defence of the beneficiary pays principle." International Theory 4, issue 2 (2012): 300-330. 
Rogelj, Joeri. et al. "Paris Agreement climate proposals need a boost to keep warming well below $2{ }^{\circ} \mathrm{C} . "$ Nature 534, (2016): 631-639.

Singer, Peter. One world: the ethics of globalization. New haven and London: Yale University Press, 2002.

Singer, Peter. "A fair deal on climate change." Project Syndicate, June 10, 2007. Available at: https://www.project-syndicate.org/commentary/a-fair-deal-on-climate-change?barrier=true. Accessed April 20, 2016.

Traxler, Martino. "Fair chore division for climate change." Social Theory and Practice 28, (2002): 101-134.

United Nations Framework Convention on Climate Change - UNFCCC. (1992). Available at: http://unfccc.int/resource/docs/convkp/conveng.pdf. Accessed April 20, 2016.

United Nations Framework Convention on Climate Change - UNFCCC. (1997). Ad Hoc Group on the Berlin Mandate. Implementation of the Berlin Mandate: Additional proposals from Parties - Addendum - Note by the secretariat. May 30, 1997. FCCC/AGBM/1997/MIS.1/Add.3.

United Nations Framework Convention on Climate Change - UNFCCC. (1997). Kyoto Protocol. Available at: http://unfccc.int/resource/docs/convkp/kpeng.pdf.

United Nations Framework Convention on Climate Change - UNFCCC (2010). Cancun Climate Change Conference. Available at: http://unfccc.int/resource/docs/2010/cop16/eng/07a01.pdf. Accessed: 20/04/2016.

United Nations Framework Convention on Climate Change - UNFCCC (2012). Report of the Conference of the Parties on its seventeenth session, held in Durban from 28 November to 11 December 2011. Available at: http://unfccc.int/resource/docs/2011/cop17/eng/09a01.pdf\#page=2. Accessed: 20/04/2016.

United Nations Framework Convention on Climate Change - UNFCCC (2014). Lima call for climate action. Available at: http://unfccc.int/files/meetings/lima_dec_2014/application/pdf/ auv_cop20_lima_call_for_climate_action.pdf

United Nations Framework Convention on Climate Change - UNFCCC (2015). Paris Agreement. Available at: https://unfccc.int/resource/docs/2015/cop21/eng/109r01.pdf. Accessed: 20/04/2016.

Viñuales, Jorge E. "Balancing Effectiveness and Fairness in the Redesign of the Climate Change Regime”. Leiden Journal of International Law 24, (2011): 223-252.

YU, Hong-Yuana and ZHU, Song-Li. "Toward Paris: China and climate change negotiations”. Advances in Climate Change Research 6, (2015): 56-66. 